Yu.L. Sayenko, T.K. Baranenko, D.N. Kalyuzhniy

\title{
FEATURES OF SELECTION OF CAPACITOR BANKS IN ELECTRIC NETWORKS WITH INTERHARMONIC SOURCES
}

\begin{abstract}
Purpose. Development of a methodology for selecting capacitor bank parameters designed to compensate for reactive power, if there are sources of interharmonics in the electrical network. Development of a methodology for selecting the parameters of capacitor banks that are part of resonant filters of higher harmonics and interharmonics. Methodology. For the research, we used the decomposition of the non-sinusoidal voltage (current) curve into the sum of the harmonic components with frequencies as multiple of the fundamental frequency - higher harmonics, and not multiple fundamental frequencies - interharmonics. Results. Expressions are obtained for checking the absence of inadmissible overloads of capacitor banks by voltage and current in the presence of voltage (current) in the curve, along with higher harmonics, of the discrete spectrum of interharmonics. When selecting capacitor banks, both for reactive power compensation and for filter-compensating devices, the necessity of constructing the frequency characteristics of the input and mutual resistances of the electrical network for analyzing possible resonant phenomena is confirmed. Originality. The expediency of simplified calculation of the voltage variation at the terminals of the banks of the capacitors of the higher harmonics filters and interharmonics due to the presence of the reactor in the filters is substantiated. Practical value. The use of the proposed approaches will make it possible to resolve a number of issues related to the choice of parameters of capacitor banks in networks with nonlinear loads, including: ensuring reliable operation of capacitor banks when their parameters deviate from their nominal values, as well as deviations in the parameters of the supply network and sources of harmonic distortion; ensuring the absence of resonant phenomena at frequencies of both higher harmonics and interharmonics. References 10.
\end{abstract}

Key words: capacitor bank, reactive power compensation, filter-compensating device, higher harmonics, interharmonics.

Разработана методика выбора батарей конденсаторов, применяемых как в качестве компенсаторов реактивной мощности при наличии источников интергармоник, так и в составе фильтров высиих гармоник и интергармоник. Получены выражения для проверки отсутствия недопустимых перегрузок батарей конденсаторов по напряэению и по току при наличии в кривой напряжения (тока), наряду с высшими гармониками, дискретного спектра интергармоник. Обоснована целесообразность упрощенного учета изменения напряжения на зажимах батарей конденсаторов фильтров высиих гармоник и интергармоник за счет наличия реактора в составе фильтров. Использование предложенных подходов позволит комплексно решать ряд вопросов, связанных с выбором параметров батарей конденсаторов в электрических сетях с нелинейными нагрузками. Библ. 10.

Ключевые слова: батарея конденсаторов, компенсация реактивной мощности, фильтро-компенсирующее устройство, высшие гармоники, интергармоники.

Introduction. Rational application of compensating devices in power supply systems allows to reduce power losses in the electric network (EN), to ensure the proper quality of the consumed electricity due to the normalization of voltage levels and, on the whole, allows achieving high technical and economic performance of electrical installations. Thus, the solution of the issues of reactive power compensation (RPC) is one of the aspects of both energy saving in EN and reliability of power supply to industrial enterprises [1-4].

Some of the most commonly used in power supply systems for various purposes of RPC devices are capacitor banks (CB), as they have a number of characteristic advantages: insignificant specific losses of active power, absence of rotating parts, simplicity of installation and operation, relatively low cost, low weight, time of work, the possibility of implementing an individual RPC $[5,6]$.

However, in modern EN there is a tendency to increase the number and power of nonlinear electric receivers. This is primarily a variety of frequency converters, rectifiers, inverters, DC drives and other semiconductor devices. Sharply varying loads are not only sources of voltage fluctuations, but also harmonic distortions of the current and voltage curves. In the presence of higher harmonics (HG) in the voltage curve, the aging process of the dielectric of capacitors proceeds more intensively than in the case when the capacitors operate at a sinusoidal voltage. This is explained by the fact that the physicochemical processes in dielectrics, which cause their aging, are significantly accelerated at high frequencies of the electric field. Analogously, the additional heating caused by the current of the HG current is affected. Depending on the frequency characteristics of the power supply systems, the CBs may be in a mode close to the resonance of the currents at the frequency of any of the HG [6-8]. Due to the overloads of the CB, they fail in the HG current. It should be noted that, depending on sources of distortion, a significant spectrum of interharmonics (IG) can be generated along with the HG, which, in accordance with the IEC standard, include harmonic oscillations with frequencies not multiples of the frequency of the supply network [6]. IG have a negative influence on the power supply systems [9]. Thus, the choice of $\mathrm{CB}$ parameters for non-sinusoidal modes should consist in preventing resonance modes at both the HG and IG frequencies and ensuring acceptable voltages on the capacitors and their allowable current loading. However, the question of the choice of CB parameters in the presence of IG is insufficiently investigated.

The goal of investigation is the development of a technique for selecting parameters of capacitor banks used both as reactive power compensators in the presence of sources of discrete spectrum of interharmonics, and in the composition of higher and interhamonic filters.

(C) Yu.L. Sayenko, T.K. Baranenko, D.N. Kalyuzhniy 
Statement of the main material. The technical conditions for the operation of the $\mathrm{CB}$ provide for limiting the excess of voltage and current above nominal values by certain values of $c_{u}$ and $c_{i}$ (in fractions of nominal values). So, according to international standards, capacitors must withstand the increased voltage of the network, which operates for a certain period of time. For example, the EN-60831-1/2 Standard specifies the requirements according to which at the industrial frequency the capacitor must withstand a voltage of $1.1 U_{\text {nom }}$ up to 8 hours per day. In addition, the capacitors must be designed for continuous operation at current not exceeding $1.3 I_{\text {nom }}$. Thus, the values of $c_{u}$ and $c_{i}$ are 1.1 and 1.3 , respectively.

Then, if there are $\mathrm{HG}$ in the voltage curve a condition of absence of unacceptable overload of the $\mathrm{CB}$ by voltage [6]:

$$
\frac{\sqrt{U_{C B}^{2}+\sum_{n=2}^{\infty} U_{n C B}^{2}}}{U_{n o m, C B}} \leq c_{u},
$$

where $U_{C B}$ is the voltage at the terminals of the $\mathrm{CB}$ at the industrial frequency (main harmonic voltage), in calculations it is allowed to use the nominal voltage of the CB $U_{n o m, C B}$ as $U_{C B} ; n$ is the number of the harmonic component; $U_{n C B}$ is the voltage of the $n$-th harmonic on capacitors.

The condition for excluding unacceptable overload of the CB by current:

$$
\frac{\sqrt{I_{C B}^{2}+\sum_{n=2}^{\infty} I_{n C B}^{2}}}{I_{n o m, C B}} \leq c_{i},
$$

where $I_{C B}$ is the current of the industrial frequency in the $\mathrm{CB}$ (main harmonic current), as in the case of voltage, it is allowed in the calculations to use the rated current $I_{\text {nom }, C B}$ as $I_{C B} ; I_{n C B}$ is the current of the $n$-th harmonic flowing through $\mathrm{CB}$.

If the discrete spectrum of the IG is present in the current and voltage curves, conditions (1) and (2) take the following form:

$$
\begin{aligned}
& \frac{\sqrt{U_{C B}^{2}+\sum_{\substack{k=1 \\
v_{k} \neq 1}}^{\infty} U_{v_{k} C B}^{2}}}{U_{n o m, C B}} \leq c_{u} ; \\
& \frac{\sqrt{I_{C B}^{2}+\sum_{\substack{k=1 \\
v_{k} \neq 1}}^{\infty} I_{v_{k} C B}^{2}}}{I_{\text {nom }, C B}} \leq c_{i},
\end{aligned}
$$

where $k$ is the number of the harmonic component of the voltage and current curves, respectively; $v_{k}$ is the relative frequency of the $k$-th harmonic component (the value of $v_{k}$ at some $k$ can coincide with the relative HG frequency $n) ; U_{v_{k} C B}$ is the voltage of the $v_{k}$-th harmonic on capacitors; $I_{v_{k} C B}$ is the current of the $v_{k}$-th harmonic flowing through $\mathrm{CB}$.
For the practical application of the condition for the absence of unacceptable overloads of the CB by voltage and current, in the presence of a discrete spectrum of the IG along with the $\mathrm{HG}$, it is advisable to reduce it to the following:

$$
\begin{aligned}
& \sqrt{1+\frac{1}{U_{\text {nom }, C B}^{2}} \sum_{\substack{k=1 \\
v_{k} \neq 1}}^{N} U_{v_{k} C B}^{2}} \leq c_{u} ; \\
& \sqrt{1+\frac{1}{I_{\text {nom }, C B}^{2}} \sum_{\substack{k=1 \\
v_{k} \neq 1}}^{N} I_{v_{k} C B}^{2}} \leq c_{i},
\end{aligned}
$$

there $N$ is the number of last harmonic taken into account.

In expressions (5) and (6), the number $N$ should be determined by the frequency range, where the harmonics have the most significant amplitudes. In the general case, the values of $N$ and $v_{N}$ will depend on the source of the IG.

Considering that the excess voltage at the terminals of the $\mathrm{CB}$ is allowed up to a value of cu (not more than 8 hours every 24 hours), and the permissible current overload to the value $c_{i}=1.3$; It is more convenient to transform (5) and (6) to the following form:

$$
\begin{aligned}
& U_{\text {nom }, C B} \geq 2.2 \sqrt{\sum_{\substack{k=1 \\
v_{k} \neq 1}}^{N} U_{v_{k} C B}^{2}} ; \\
& I_{\text {nom }, C B} \geq 1.2 \sqrt{\sum_{\substack{k=1 \\
v_{k} \neq 1}}^{N} I_{v_{k} C B}^{2}} .
\end{aligned}
$$

Verification of the absence of resonant modes during the operation of the $\mathrm{CB}$ connected to a network with nonsinusoidal sources can be performed by analyzing the frequency characteristics of the corresponding EN. Frequency characteristics of EN can be obtained both experimentally and by calculation. The method for calculating the resonant modes in EN involves the construction of a circuit for replacing the network under consideration, determining the parameters of the replacement circuit at harmonic frequencies and calculating the frequency characteristics of the input and mutual resistances (or conductances) of network nodes at harmonic frequencies [10].

On the basis of the obtained replacement scheme, a matrix of nodal conductivities of the EN at the frequency of the $n$-th harmonic is formed:

$$
Y_{y n}=\left[\begin{array}{cccc}
Y_{11 n} & Y_{12 n} & \cdots & Y_{1 m n} \\
Y_{21 n} & Y_{22 n} & \cdots & Y_{2 m n} \\
\vdots & & & \vdots \\
Y_{m 1 n} & Y_{m 2 n} & \cdots & Y_{m m n}
\end{array}\right] .
$$

Each of the diagonal elements of this matrix corresponds to a specific node of the system and is equal to the sum of the conductivities of all branches directly connected to this node. The off-diagonal elements are equal to the conductivities of the corresponding branches connecting the given pair of nodes taken with the minus sign. In the absence of such branches, the off-diagonal element is assumed to be zero. 
The input resistance of the $\mathrm{EN}$ on the side of the node with the number $i$ at the frequency of the $n$-th harmonic can be found as [10]

$$
Z_{\text {iin }}=\frac{A_{i i n}}{D_{n}},
$$

where $D_{n}$ is the determinant of the matrix of nodal conductances (9) at the frequency of the $n$-th harmonic; $A_{\text {iin }}$ is the algebraic complement of the determinant $D_{n}$.

Mutual (transfer) resistance of the $i$-th and $j$-th nodes of the $\mathrm{EN}$ at the frequency of the $n$-th harmonic is

$$
Z_{i j n}=\frac{A_{i j n}}{D_{n}},
$$

where $A_{i j n}$ is the algebraic complement of the determinant $D_{n}$.

Algebraic complements $A_{i i n}$ and $A_{i j n}$ can be found as

$$
\begin{gathered}
A_{i i n}=D_{i i n} ; \\
A_{i j n}=(-1)^{i+j} D_{i j n},
\end{gathered}
$$

where $D_{i i n}$ is the minor obtained from the determinant $D_{n}$ deleting the $i$-th row and the $i$-th column; $D_{i j n}$ is the the minor obtained from the determinant $D_{n}$ deleting the $i$-th row and the $j$-th column.

At frequencies corresponding to the frequencies of the resonances of the currents, the values of the input and mutual resistances of the nodes will tend to infinity (if the active resistances are neglected). At resonances of currents, a relatively small harmonic current, whose frequency coincides with the resonance frequency, causes considerable stresses at the network nodes (due to large input and mutual resistances of the nodes). This leads to the flow of significant currents in the branches of the network and the overload of the CB.

Due to the fact that changes in the EN occur in the frequency characteristics of the input and mutual resistances caused by changes in the resistance of the mains power, the capacities and modes of the connected loads, and possible switchings in the circuit, it is necessary to take into account these factors and determine possible ranges of changes in the resonance frequencies.

The approach taken to the choice of $\mathrm{CB}$ parameters used for RPC is also valid for the selection of the CB that are part of the filter-compensating devices (FCD) used to reduce the voltage nonsinusoidal and, at the same time, the RPC.

The presence of the reactor in the composition of the filter changes the voltage at the terminals of the $\mathrm{CB}$ by a value that depends on the frequency of the filter setting $v$ [6],

$$
U_{C B}=a_{v} U_{e n},
$$

where $U_{e n}$ is the linear (phase) voltage of the electric network; $a_{v}$ is the voltage change coefficient.

Without account of the active resistance of the filter circuit

$$
a_{v}=\frac{v^{2}}{v^{2}-1} .
$$

Since all elements of the filter circuit have active resistance (terminals of capacitors, reactors, bus bars, cables, etc.), then taking into account the active resistance, the voltage change coefficient is determined by the expression [6]

$$
a_{v}=\frac{v^{2} \operatorname{tg} \varphi_{r}}{\sqrt{\operatorname{tg}^{2} \varphi_{r}\left(v^{2}-1\right)^{2}+1}},
$$

where $\operatorname{tg} \varphi_{r}=x_{r} / R_{f} ; x_{r}$ is the filter reactor's resistance depending from the resonant condition; $R_{f}$ is the total active resistance of the filter circuit.

The ratio $x_{r} / R_{f}$ is the $Q$ of the contour. Thus, we can write $\operatorname{tg} \varphi_{r}=Q$. For the FCD of the HG $Q \geq 10$ [10], according to the investigations carried out for the FCD IG, especially installed in the low-frequency band, the inequality $Q \geq 10$ is also satisfied.

Calculations have shown that the determination of the coefficient $a_{v}$ from expression (15) gives an error in the direction of increase, in comparison with the coefficient $a_{v}$ determined by the expression (16), by not more than $1 \%$ at $Q=10$, with the exception of the range $0.55 \leq v \leq 0.7$. In the indicated range, the maximum error for $v=0.7$ is $1.9 \%$. As the quality factor increases, the error decreases significantly. So, for example, even at $Q=20$, the error of calculating $a_{v}$ from expression (15) for all frequencies entering the possible zones of the FCD IG unit is less than $1 \%$.

Thus, when choosing the nominal voltage of the CB of the IG filters, the coefficient $a_{v}$ should be determined in accordance with (15). In this case, a slight overestimation of the rated voltage is possible, which is preferable from the point of view of reliable operation of the CB filters when they are detuned.

Taking into account the expressions (5) and (14), the condition for the absence of an unacceptable overload of the $\mathrm{CB}$ of the FCD tuned to the frequency $v$, by voltage:

$$
\sqrt{a_{v}^{2} k_{U}^{2}+\frac{1}{U_{n o m, C B}^{2}} \sum_{\substack{k=1 \\ v_{k} \neq 1}}^{N} U_{v_{k} C B}^{2}} \leq c_{u}=1.1,
$$

где $k_{U}=\frac{U_{e n}}{U_{n o m, C B}}$.

The CB current $I_{C B}$ is proportional to the voltage on the bank $U_{C B}$, therefore we can write [10]

$$
I_{C B}=I_{n o m, C B} a_{v} k_{U} \text {. }
$$

Substituting (18) into (6), after the transformations, we obtain the condition for the absence of an unacceptable overload of the CB of the FCD by current:

$$
\sqrt{a_{v}^{2} k_{U}^{2}+\frac{1}{I_{n o m, C B}^{2}} \sum_{\substack{k=1 \\ v_{k} \neq 1}}^{N} I_{v_{k} C B}^{2}} \leq c_{i}=1.3 .
$$

Conclusions. When choosing capacitor banks for both reactive power compensation and filtercompensating devices, it is necessary to build the frequency characteristics of the input and mutual resistances of the electrical network for analyzing possible resonant phenomena, both in the node with the source of the interharmonics, and in all other nodes of the network. When building frequency characteristics, it is necessary to take into account the active resistances of the elements of the electrical network, which have 
a significant effect on the impedance at resonance of currents.

When choosing the parameters of the filter capacitor banks, a complex solution of a whole range of issues is necessary including ensuring their reliable operation when the parameters of both the filters themselves and the power supply network are disturbed, sources of harmonic distortion from nominal ones; the absence of resonant phenomena at the frequencies of both higher harmonics and interharmonics. The solution of these questions requires: calculation of the spectral composition of the currents of the sources of higher harmonics and interharmonics, rational selection of the zone(s) for the installation of the filter-compensating device, as accurate as possible calculation of the actual frequency of the filter adjustment and the possible range of its deviations.

\section{REFERENCES}

1. Zaytsev I. M. On compensation of reactive power of electrical equipment. Energy saving. Power engineering. Energy audit, 2010, no.11, pp. 66-69. (Ukr).

2. Omelchuk A.O., Skripnik A.M., Trondyuk V.S. Concerning the balance of reactive power in power grids in the new normative conditions of jet energy flows in Ukraine. Scientific Herald of National University of Life and Environmental Sciences of Ukraine. Series: Technique and energy of APK, 2011, no. 161, pp. 111-119. (Ukr).

3. Seema Dudhe. Reactive Power Compensation Techniques in Transmission lines. International Journal on Recent and Innovation Trends in Computing and Communication (IJRITCC), 2015, vol. 3, iss. 5, pp. 3224-3226.

4. Dixon J., Moran L., Rodriguez J., Domke R. Reactive Power Compensation Technologies: State-of-the-Art Review. Proceedings of the IEEE, 2005, vol.93, iss.12, pp. 2144-2164. doi: 10.1109/JPROC.2005.859937.

5. Davidov O.Yu., Byalobrzheskiy O.V. Analysis of reactive power compensation systems in electrical engineering systems. Transactions of Kremenchuk Mykhaylo Ostrogradskiy State University, 2010, no.3(62), pp. 132-136. (Ukr).
6. Zhezhelenko I.V., Saenko Yu.L. Kachestvo elektroenergii na promushlennukh predpriiatiiakh [Power quality in industrial plants]. Moscow, Energoatomizdat Publ., 2005. 261 p. (Rus).

7. Attachie J.C., Amuzuvi C.K. Using a Fixed and SwitchedCapacitor Bank to Investigate Harmonic Resonance and Capacitor Bank Switching in a Distribution Network. Research Journal of Applied Sciences, Engineering and Technology, 2014, vol.7, iss.9, pp. 1900-1909. doi: 10.19026/rjaset.7.480.

8. Wilsun $\mathrm{Xu}, \mathrm{Xian} \mathrm{Liu}, \mathrm{Yilu}$ Liu. Assessment of harmonic resonance potential for shunt capacitor applications. Electric Power Systems Research, 2001, vol.57, iss.2, pp. 97-104, doi: 10.1016/S0378-7796(01)00092-X.

9. Saenko Yu.L., Baranenko T.K., Baranenko E.V. Reduction of levels of harmonic distortions in electric networks with sources of interharmonics. Electrification of transport, 2012, no.3, pp. 78-83. (Ukr).

10. Zhezhelenko I.V., Saenko Yu.L., Baranenko T.K., Gorpinich A.V., Nesterovich V.V. Izbrannye voprosy nesinusoidal'nykh rezhimov $v$ elektricheskikh setiakh predpriiatii [Selected issues of non-sinusoidal regimes in electric networks of enterprises]. Moscow, Energoatomizdat Publ., 2007. 296 p. (Rus).

Received 19.08.2017

Yu.L. Sayenko ${ }^{1}$, Doctor of Technical Science, Professor,

T.K. Baranenko ${ }^{1}$, Candidate of Technical Science, Associate Professor,

D.N. Kalyuzhniy ${ }^{2}$, Candidate of Technical Science, Associate

Professor,

${ }^{1}$ Pryazovskyi State Technical University,

7, Universytets'ka Str., Mariupol, 87500, Ukraine, phone +380629446551 ,

e-mail: yls62@i.ua, tbaranenko@gmail.com

${ }^{2}$ O.M. Beketov National University of Urban Economy in Kharkiv,

12, Revolution Str., Kharkiv, 61002, Ukraine, phone +380 577073117 ,

e-mail: KalyuzhniyDN@gmail.com

How to cite this article:

Sayenko Yu.L., Baranenko T.K., Kalyuzhniy D.N. Features of selection of capacitor banks in electric networks with interharmonic sources. Electrical engineering \& electromechanics, 2017, no.5, pp. 67-70. doi: 10.20998/2074-272X.2017.5.11. 